\title{
Strategi Peningkatan Kinerja UMKM melalui "UMKM Naik Kelas" Pada UMKM di Kecamatan Cempaka Putih Jakarta Pusat
}

\author{
Sutandi ${ }^{1}$, Resista Vikaliana ${ }^{2}$, Yusup Rachmat Hidayat ${ }^{3}$, Yuli Evitha ${ }^{4}$ \\ Institut Ilmu Sosial dan Manajemen STIAMI, Jakarta, Indonesia 1,2,3,4 \\ resistav31@gmail.com
}

ARTICLE INFO

Keywords

UMKM Grades Up

Marketing Go Online

Simple Financial Reports

UMKM Tax Socialization
ABSTRACT

In Indonesia, SMEs have a strategic role and a very large contribution to the national economy by contributing $53.3 \%$ of total GDP (Gross Domestic Product). The number of SMEs in Indonesia reaches around 56.2 million units and is capable of absorbing $97.2 \%$ of the total workforce. Based on data from the Central Statistics Agency (BPS) the growth of online-based trading business has increased in the last 10 years, to 26 million or up $17 \%$ and followed by the number of SMEs reaching more than 55 million units, but many challenges must be faced by SMEs in facing MEA.

The form of community service activity training is titled: "UMKM Grades Up with the subtitles Training on Inventory Management, Marketing Go Online, and Preparation of Simple Financial Statements and MSME Tax Socialization".

This year 2019 is the second year of the implementation of this community service program. This year, the response of community service partners, in this case 10 Assisted Culinary MSMEs around the campus, Cempaka Putih Jakarta, were very enthusiastic. This can be seen from the spirit of curiosity (many questions) about the material of socialization and the seriousness of the training that was given. The UMKM Actors asked for the continuation of this training, in the form of assistance / consultation for the development of the UMKM.

The driving factors of the UMKM Graduation Class activities are the enthusiasm or high motivation of the SMEs. While the obstacle to the implementation of this program is the lack of duration of training, in terms of frequency. Another difficulty is the limited time of the UMKM Actors, because they have to take care of the UMKM business processes that are still running.

Based on the results and outcomes achieved in 2019 community service titled MSMEs Graduating Classes, then for 2020 it is planned to hold: mentoring MSME business processes, so that MSMEs truly advance in class. The intended grade is that there is progress in management, so that it has implications for increasing MSME income. To facilitate the assistance for MSME business development, a MSME staging or clustering will be conducted in Cempaka Putih District.

\section{A. PENDAHULUAN}

Di Indonesia, UKM memiliki peran strategis dan kontribusi sangat besar bagi perekonomian Nasional dengan menyumbang 53,3\% dari total PDB (Pendapatan Domestik Bruto). Jumlah UKM di Indonesia mencapai sekitar 56,2 juta unit dan mampu menyerap 97,2\% tenaga kerja dari total angkatan tenaga kerja yang ada. Berdasarkan data Badan Pusat Statistik (BPS) pertumbuhan usaha perdagangan berbasis online ini meningkat dalam 10 tahun terakhir, menjadi 26 juta lebih atau naik 17\% serta diikuti dengan jumlah pelaku UKM mencapai 55 juta unit lebih.

Tetapi banyak tantangan yang harus dihadapi oleh UKM dalam menghadapi MEA dan era digital antara lain yaitu : (1) Pola pikir masyarakat Indonesia masih lebih cenderung mengkonsumsi 
produk atau jasa dari luar negeri dibandingkan dari dalam negeri. (2) Masih lemahnya infrastruktur seperti akses transportasi menyebabkan biaya ekonomi menjadi lebih tinggi terutama juga bagi sektor produksi dan bagi pasar. (3) UKM menghadapi keterbatasan akses finansial karena masih adanya keraguan bank terhadap UKM dalam memberikan pinjaman. (4) Keterbatasan UKM dalam memanfaatkan teknologi karena kurangnya pengetahuan dan akses sehingga aktivitas promosi terbatas dan menjadi penghambat bagi UKM untuk memperluas target pasarnya dalam menghadapi MEA(Ragimun, Sudaryanto, \& Wijayanti, 2015). (5) Investasi UKM pada pengembangan dan penelitian produk atau jasa masih sangat rendah karena UKM lebih fokus kepada pemasaran atau kebutuhan operasionalnya. (6) Banyak UKM yang belum memiliki perencanaan bisnis yang belum matang. Salah satu cara untuk membuat perencanaan yang baik bisa dengan menggunakan jasa konsultasi dan informasi.

Beberapa upaya pemerintah membantu meningkatkan daya saing koperasi dan UMKM (Vikaliana, Harsanti, Wulandari, \& Andayani, 2017)agar tumbuh dengan skala yang lebih besar dan berkelanjutan dalam rangka mendukung kemandirian perekonomian nasional antara lain dengan Program Kredit Usaha Rakyat, Program UMKM Go Online, Pemberian HAKI, dan Promosi melalui Galeri Indonesia WOW. Tetapi beberapa program di atas masih belum menyentuh masyarakat secara luas sehingga diperlukan sosialisasi oleh semua pihak untuk meningkatkan akses informasi UMKM.

Berdasarkan fenomena di atas, maka diperlukan suatu kegiatan pengabdian masyarakat bagi UMKM untuk dapat memperoleh pengetahuan keuangan, sehingga dapat mengakses penambahan modal usaha (Anggraeni, Puspitasari, El Ayyubi, \& Wiliasih, 2018). Pengembangan usaha yang dimaksud adalah pengajuan Kredit Usaha Rakyat/ KUR dan pengelolaan keuangan yang benar(Kurniawati, Nugroho, \& Arifin, 2010). Pada kegiatan ini, difokuskan pada pengelolaan persediaan, marketing go online, dan penyusunan laporan keuangan sederhana serta sosialisasi pajak UMKM. Kegiatan ini diberi judul: "UMKM Naik Kelas dengan sub judul Pelatihan Pengelolaan Persediaan, Marketing Go Online, dan Penyusunan Laporan Keuangan Sederhana serta Sosialisasi Pajak UMKM".

\section{Permasalahan Mitra}

Mitra pengabdian masyarakat ini adalah 11 UMKM di Kecamatan Cempaka Puth Jakarta Pusat Propinsi DKI Jakarta. Permasalahan yang dihadapi adalah pengelolaan proses bisnisnya, khususnya terkait keuangan dan pemasaran.

\section{Solusi yang Ditawarkan}

Solusi yang ditawarkan untuk mitra, dalam hal ini UMKM di Kecamatan Cempaka Putih Jakarta Pusat dengan training/ pelatihan pengelolaan persediaan, marketing go online, keterampilan mengelola keuangan melalui pelatihan penyusunan keuangan sederhana dan sosialisasi pajak UMKM.

Target dari kegiatan UMKM Naik Kelas ini adalah meningkatkan keterampilan UMKM di Kecamatan Cempaka Putih dengan pengetahuan pengelolaan UMKM dari sisi persediaan dan pemasaran/ marketing, serta pengetahuan keuangan dan pajak untuk meningkatkan pengelolaan keuangan dan memperluas modal kerja (misal pengajuan peminjaman modal ke bank atau lembaga keuangan lain). Sedangkan luaran pengabdian kepada masyarakat UMKM Naik Kelas di Kecamatan Cempaka Putih Jakarta Pusat ini . diharapkan menghasilkan outcomes UMKM di Wilayah Cempaka Putih. Luaran sehingga dapat meningkatkan kapabilitasnya dalam menaikkan pendapatan UMKM.

\section{B. METODE PELAKSANAAN KEGIATAN}

\section{Tujuan Kegiatan}

Kegiatan pengabdian kepada masyarakat "UMKM Naik Kelas dengan sub judul Pelatihan Pengelolaan Persediaan, Marketing Go Online, dan Penyusunan Laporan Keuangan Sederhana serta Sosialisasi Pajak UMKM". . bertujuan:

a. Mengimplementasikan Tri Dharma Perguruan Tinggi, khususnya pengabdian kepada masyarakat. 
b. Menjalin kerjasama yang saling menguntungkan antara lingkungan akademik dengan masyarakat/UMKM.

c. Mengembangkan skala usaha UMKM melalui peningkatan pengelolaan proses bisnis dalam pengelolaan persediaan, pemasaran online/ marketing go online, pengetahuan penyusunan laporan keuangan serta pengetahuan perpajakan

\section{HASIL DAN PEMBAHASAN}

\section{Susunan Tim Pelaksana}

Kegiatan pengabdian masyarakat ini merupakan kegiatan lintas program studi/ prodi. Prodi yang terlibat adalah manajemen logistik, administrasi bisnis, akuntansi bisnis dan administrasi perpajakan. Kegiatan ini bekerja sama dengan BI Corner yang ada di Perpustakaan Kampus Pusat Institut Stiami, Cempaka Putih, Jakarta Pusat.

\section{Bentuk Kegiatan, Waktu, dan Tempat Kegiatan}

Bentuk kegiatan pengabdian kepada masyarakat ini pelatihan berjudul: UMKM Naik Kelas dengan sub judul

1. Pelatihan Pengelolaan Persediaan

2. Pelatihan Marketing Go Online

3. Pelatihan Penyusunan Laporan Keuangan Sederhana

4. Sosialisasi Pajak UMKM

Kegiatan dilaksanakan dengan rincian sebagai berikut:

Tabel 1 .Jadwal Kegiatan

\begin{tabular}{|c|c|c|c|}
\hline \multicolumn{4}{|c|}{16 November 2019} \\
\hline WAKTU & URAIAN KEGIATAN & TEMPAT & $\begin{array}{l}\text { PENANGGUNG } \\
\text { JAWAB }\end{array}$ \\
\hline 10.00-11.00 WIB & $\begin{array}{l}\text { Pelatihan Pengelolaan } \\
\text { Persediaan }\end{array}$ & \multirow{3}{*}{$\begin{array}{c}\text { BI Corner } \\
\text { Perpustakaan } \\
\text { Kampus Institut } \\
\text { STIAMI }\end{array}$} & $\begin{array}{c}\text { Tim Prodi } \\
\text { Manajemen Logistik }\end{array}$ \\
\hline 11.00-12.00 WIB & $\begin{array}{l}\text { Pelatihan Pemasaran/ } \\
\text { Marketing Goonline }\end{array}$ & & $\begin{array}{c}\text { Tim Prodi } \\
\text { Administrasi Bisnis }\end{array}$ \\
\hline 12.00-13.00 WIB & ISHOMA dan Diskusi & & \\
\hline \multicolumn{4}{|c|}{23 November 2019} \\
\hline WAKTU & URAIAN KEGIATAN & TEMPAT & $\begin{array}{c}\text { PENANGGUNG } \\
\text { JAWAB }\end{array}$ \\
\hline $10.00-10.30 \mathrm{WIB}$ & $\begin{array}{l}\text { Sosialisasi Pajak } \\
\text { UMKM }\end{array}$ & \multirow{3}{*}{$\begin{array}{c}\text { BI Corner } \\
\text { Perpustakaan } \\
\text { Kampus Institut } \\
\text { STIAMI }\end{array}$} & $\begin{array}{l}\text { Tim Prodi } \\
\text { Administrasi } \\
\text { Perpajakan }\end{array}$ \\
\hline $10.30-11.30$ & $\begin{array}{l}\text { Pelatihan Penyusunan } \\
\text { Laporan Keuangan } \\
\text { Sederhana }\end{array}$ & & $\begin{array}{c}\text { Tim Prodi Akuntansi } \\
\text { Bisnis }\end{array}$ \\
\hline $11.30-12.00$ & ISHOMA dan Diskusi & & \\
\hline
\end{tabular}

Tahun 2019 ini merupakan tahun kedua pelaksanaan program pengabdian masyarakat ini. Pada tahun ini, respon mitra pengabdian masyarakat, dalam hal ini 10 UMKM Kuliner Binaan di sekitar kampus, 
Cempaka Putih Jakarta, adalah sangat antusias. Hal ini terlihat dari semangat ingin tahu (banyak pertanyaan) tentang materi sosialisasi dan keseriusan mengikuti pelatihan yang diberikan. Para Pelaku UMKM tersebut meminta keberlanjutan dari pelatihan ini, berupa pendampingan/ konsultasi pengembangan UMKMnya.

Faktor-faktor pendorong kegiatan UMKM Naik Kelas adalah antusias atau motivasi yang tinggi dari para Pelaku UMKM. Sedangkan penghambat pelaksanaan program ini adalah kurang lamanya durasi waktu pelatihan, dalam hal frekwensi. Kesulitan lainnya adalah keterbatasan waktu Para Pelaku UMKM, karena harus mengurusi proses bisnis UMKMnya tetap berjalan.

Berdasarkan hasil dan luaran yang dicapai pada pengabdian masyarakat tahun 2019 berjudul UMKM Naik Kelas, maka untuk tahun 2020 direncanakan untuk mengadakan: pendampingan proses bisnis UMKM, supaya UMKM tersebut benar-benar naik kelas. naik kelas yang dimaksud adalah terdapat kemajuan dalam pengelolaan, sehingga berimplikasi pada peningkatan pendapatan UMKM. Untuk mempermudah pendampingan pengembangan usaha UMKM, akan dilakukan pemetaan atau klusterisasi UMKM di Kecamatan Cempaka Putih.

\section{Rencana Tahapan Berikutnya}

Berdasarkan hasil dan luaran yang dicapai pada pengabdian masyarakat tahun 2018 berjudul UMKM Naik Kelas, maka untuk tahun 2019 direncanakan untuk mengadakan pendampingan proses bisnis UMKM, supaya UMKM tersebut benar-benar naik kelas. naik kelas yang dimaksud adalah terdapat kemajuan dalam pengelolaan, sehingga berimplikasi pada peningkatan pendapatan UMKM. Untuk mempermudah pendampingan pengembangan usaha UMKM, akan dilakukan pemetaan atau klusterisasi UMKM di Kecamatan Cempaka Putih.

\section{Foto-foto Kegiatan}

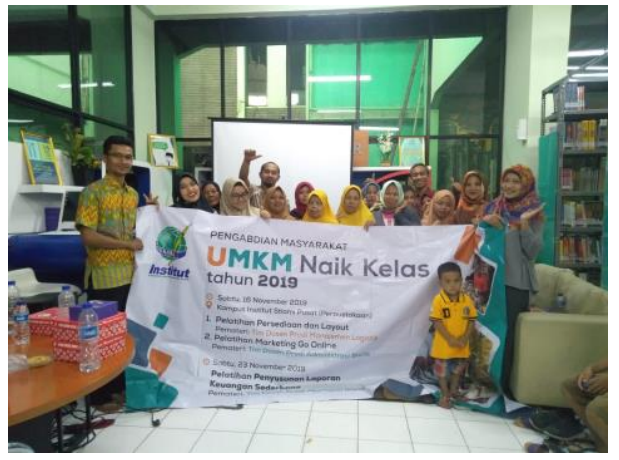

Gambar 1. 16 November 2019

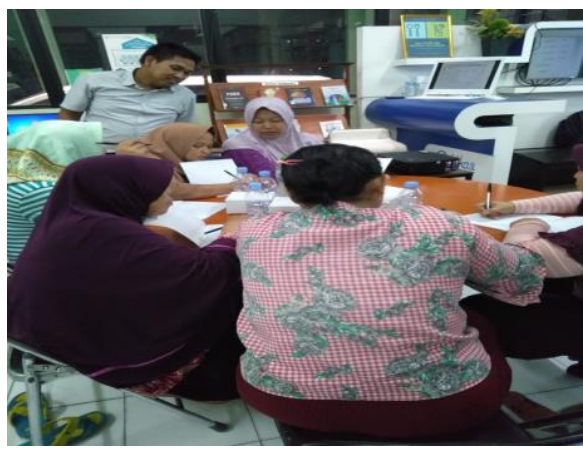

Gambar 3. 23 November 2019

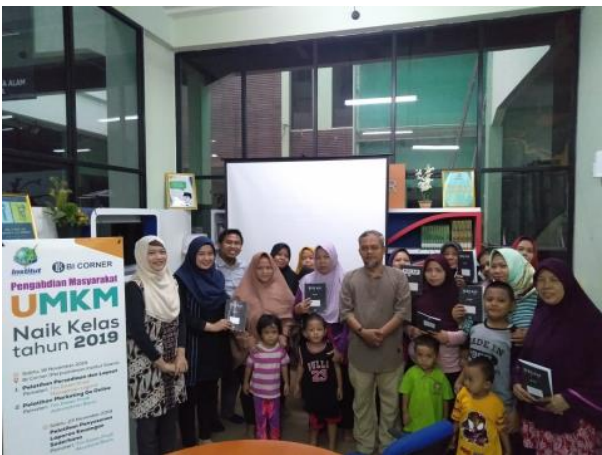

Gambar 2. 23 November 2019

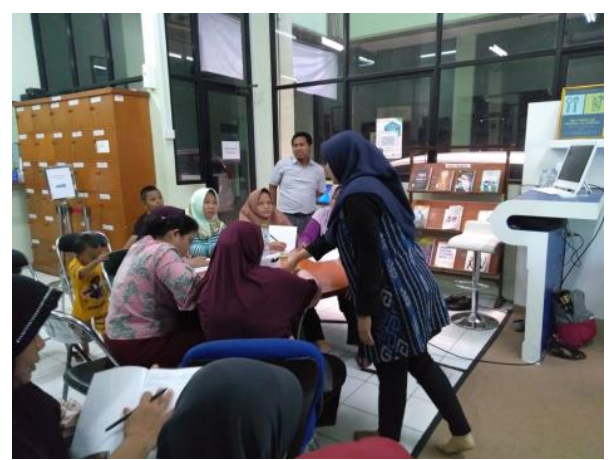

Gambar 4. 23 November 2019 


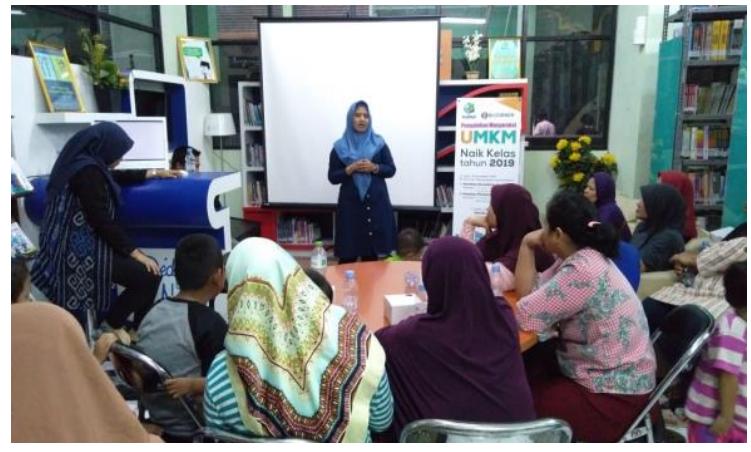

Gambar 5. 23 November 2019

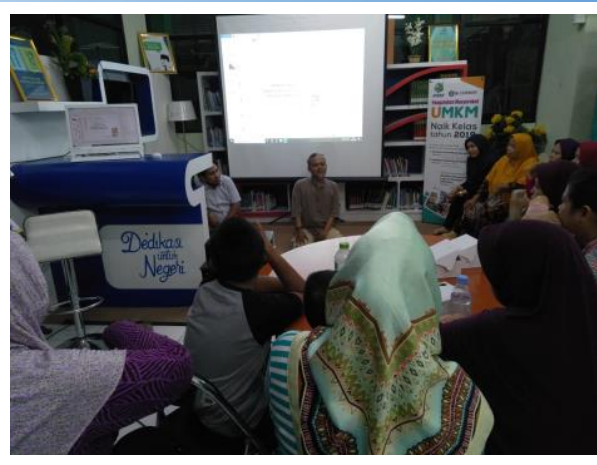

Gambar 6. 23 November 2019

\section{SIMPULAN DAN SARAN}

\section{Simpulan}

Bentuk kegiatan pengabdian kepada masyarakat ini Pelatihan Pengelolaan Persediaan, Marketing Go Online, dan Penyusunan Laporan Keuangan Sederhana serta Sosialisasi Pajak UMKM

Tahun 2019 ini merupakan tahun kedua pelaksanaan program pengabdian masyarakat ini. Pada tahun ini, respon mitra pengabdian masyarakat, dalam hal ini 10 UMKM Kuliner Binaan di sekitar kampus, Cempaka Putih Jakarta, adalah sangat antusias. Hal ini terlihat dari semangat ingin tahu (banyak pertanyaan) tentang materi sosialisasi dan keseriusan mengikuti pelatihan yang diberikan. Para Pelaku UMKM tersebut meminta keberlanjutan dari pelatihan ini, berupa pendampingan/ konsultasi pengembangan UMKMnya.

Faktor-faktor pendorong kegiatan UMKM Naik Kelas adalah antusias atau motivasi yang tinggi dari para Pelaku UMKM. Sedangkan penghambat pelaksanaan program ini adalah kurang lamanya durasi waktu pelatihan, dalam hal frekwensi. Kesulitan lainnya adalah keterbatasan waktu Para Pelaku UMKM, karena harus mengurusi proses bisnis UMKMnya tetap berjalan.

\section{Saran}

Berdasarkan hasil dan luaran yang dicapai pada pengabdian masyarakat tahun 2019 berjudul UMKM Naik Kelas, maka untuk tahun 2020 direncanakan untuk mengadakan: pendampingan proses bisnis UMKM, supaya UMKM tersebut benar-benar naik kelas. naik kelas yang dimaksud adalah terdapat kemajuan dalam pengelolaan, sehingga berimplikasi pada peningkatan pendapatan UMKM. Untuk mempermudah pendampingan pengembangan usaha UMKM, akan dilakukan pemetaan atau klusterisasi UMKM di Kecamatan Cempaka Putih.

\section{DAFTAR PUSTAKA}

Anggraeni, L., Puspitasari, H., El Ayyubi, S., \& Wiliasih, R. (2018). Akses UMKM terhadap Pembiayaan Mikro Syariah dan Dampaknya terhadap Perkembangan Usaha: Kasus BMT Tadbiirul Ummah, Kabupaten Bogor. Al-Muzara'ah, 1(1), 56-67. https://doi.org/10.29244/jam.1.1.56-67

Kurniawati, E. P., Nugroho, P. I., \& Arifin, C. (2010). Penerapan Akuntansi pada Usaha Mikro Kecil dan Menengah (UMKM). Informatics and Business Institute Darmajaya, 10(2). https://doi.org/jurnal.darmajaya.ac.id/index.php/jmk/article/view/332

Ragimun, Sudaryanto, \& Wijayanti, R. R. (2015). Strategi Pemberdayaan UMKM Menghadapi Pasar Bebas Asean. Web Kementerian Keuangan, 1-32.

Vikaliana, R., Harsanti, D., Wulandari, D. S., \& Andayani, A. (2017). A Cluster Model for Increasing Performance of Small and Medium-Scale Enterprises (A Case Study in Bogor, Indonesia). Springer, Singapore. https://doi.org/https://doi.org/10.1007/978-981-287-661-4_15 